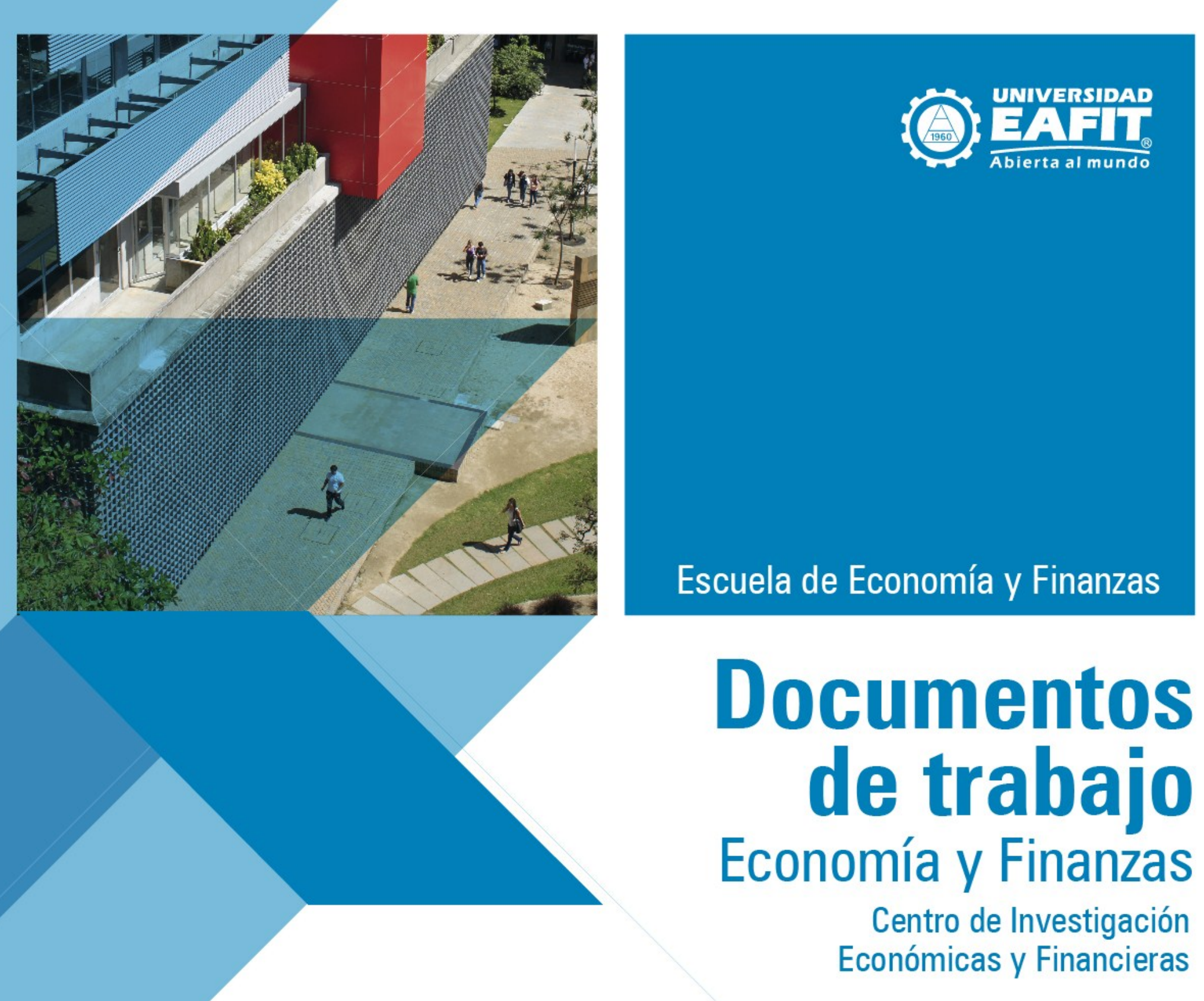

No. 16-26 Absolute Inequality and Violent Property 2016 Crime

Thomas Goda, Alejandro Torres García

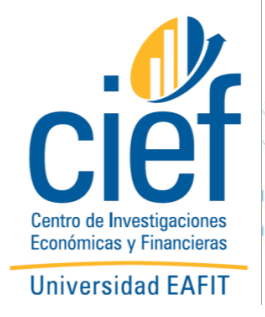




\title{
Absolute Inequality and Violent Property Crime
}

\author{
Thomas Goda $a^{a}$ and Alejandro Torres García ${ }^{b}$
}

August 2016

\begin{abstract}
Rational choice models argue that income inequality leads to a higher expected utility of crime and thus generates incentives to engage in illegal activities. Yet, the results of empirical studies do not provide strong support for this theory; in fact, Neumayer provides apparently strong evidence that income inequality is not a significant determinant of violent property crime rates when a representative sample is used and country specific fixed effects are controlled for. An important limitation of this and other empirical studies on the subject is that they only consider proportional income differences, even though in rational choice models absolute difference in legal and illegal incomes determine the expected utility of crime. Using the same methodology and data as Neumayer, but using absolute inequality measures rather than proportional ones, this paper finds that absolute income inequality is a statistically significant determinant of robbery and violent theft rates. This result is robust to changes in sample size and to different absolute inequality measures, which not only implies that inequality is an important correlate of violent property crime rates but also suggests that absolute measures are preferable when the impact of inequality on property crime is studied.
\end{abstract}

Key Words: Violent Crime; Property Crime; Income Inequality, Absolute Inequality JEL Classification: D31; D63; K42

${ }^{a}$ Universidad EAFIT, School of Economics and Finance, Carrera 49 Número 7 Sur 50, Medellín, Colombia; email: tgoda@eafit.edu.co; phone: (57) 42619500 -8664; fax: (57) 42619294 (corresponding author)

${ }^{\mathrm{b}}$ Universidad EAFIT, School of Economics and Finance, Carrera 49 Número 7 Sur 50, Medellín, Colombia; email: atorres7@eafit.edu.co; phone: (57) 42619500 - 8664; fax: (57) 42619294

We are grateful to Angelica Sanchez and Alfredo Villca for their outstanding research assistance. Furthermore, we would like to thank Andrés Ramirez, Gustavo Canavire, the participants of the conference "Inequality, Trust and Ethics: Insights from Economics and Behavioral Ethics" (hosted by the University of Notre Dame in London in May 2015) and the participants of the Economics Seminar at the Universidad Javeriana in Bogotá for their helpful comments. We gratefully acknowledge funding from Colombia's Administrative Department of Science, Technology and Innovation (Colciencias) for research assistance. Finally, we appreciate that the Journal of Peace Research provided a dataset that allowed us to replicate the article "Inequality and Violent Property Crime: Evidence from Data on Robbery and Violent Theft" (Neumayer, 2005). 


\section{Introduction}

The determinants of crime rates have been a topic of interest to criminologists, sociologists and economists for decades. Several theories—-such as strain theory (Merton, 1938; Agnew, 1985) and rational choice theory (Ehrlich, 1973; Chiu and Madden, 1998)-argue that economic inequality is an important factor in explaining why people perpetrate crimes. Henceforth, income inequality has been among the main variables considered in empirical cross-country studies on the correlates of crime.

While a broad empirical consensus exists that inequality is a strong predictor of differences in homicide rates across countries (Nivette, 2011), the evidence for the impact of inequality on property crimes is inconclusive. Some studies present results that support the hypothesis that inequality fosters property crime (e.g., Bennett, 1991; Fanjzylber et al., 2002a, 2002b; Soares, 2004a, 2004b), whereas other studies do not find a significant relationship (e.g., Stack, 1984; Neapolitan, 1995; Neumayer, 2005, Sun et al., 2011).

In particular, the contradictory results of Fanjzylber et al. (2002a, 2002b) and Neumayer (2005) merit attention. Fanjzylber et al.'s widely cited studies find that inequality is a significant and robust determinant of violent property crime even if unobservable country specific factors are controlled for, whereas Neumayer's findings suggest that these results are biased by the sample size. To be more precise, using a similar methodology as Fanjzylber et al., Neumayer finds that "if we allow for a more representative sample ... then income inequality is no longer a statistically significant determinant of violent property crime" (2005: 110).

One important shortcoming of existing cross-country studies on the correlates of crime is that they employ relative inequality measures that account for the average disproportionality of incomes between households (such as the Gini Index or top-to-bottom income ratios). This focus on relative inequality seems unduly restrictive considering that rational choice models argue that the expected utility of crime is determined by the absolute difference between legal and illegal incomes (Ehrlich, 1973; Chiu and Madden, 1998). Hence, from an 
economic point of view, absolute inequality measures (such as the variance and the difference between top and bottom incomes expressed in monetary terms) should be used to verify if income inequality is a significant determinant of property crime. ${ }^{1}$

Existing cross-country studies may choose to consider relative inequality measures instead of absolute ones because the former are readily available for many countries, easy to interpret and widely used in a broad range of other socio-economic contexts. However, absolute measures fulfill the same technical properties as their relative counterparts (see Chakravarty, 2001), and the data requirements for their calculation are identical. The omission of absolute measures is therefore puzzling, especially when one considers that the above-mentioned property of rational choice models of crime is acknowledged by the empirical crime literature and that it is widely accepted that the differentiation between relative and absolute inequality is far from trivial. It has been shown, for example, that relative and absolute global inequality trends differ considerably (Ravallion, 2004; Atkinson and Brandolini, 2010; Bosmans et al., 2014; Goda, 2016; Goda and Torres García, 2016).

Accordingly, it is not clear if the findings of the existing literature are influenced by their decision to consider only relative inequality measures. The aim of this paper is to help fill this gap in the literature by testing if absolute income inequality is a significant and robust determinant of violent property crime. To ensure that our results are not influenced by the data and methodology used, we employ the same research design as Neumayer (2005), with the major difference that our inequality proxies are the variance and the absolute income difference between the top and bottom incomes (instead of the Gini coefficient and the topto-bottom-ratio).

\footnotetext{
${ }^{1}$ To make the difference between absolute and relative inequality palpable, suppose that a country has two citizens ( $\mathrm{P}$ and $\mathrm{R}$ ) with respective incomes of $\$ 100$ and $\$ 1,000$. When viewed in relative terms, $\mathrm{R}$ has ten times the income of $\mathrm{P}$, whereas in absolute terms, $\mathrm{R}$ has $\$ 900$ more than $\mathrm{P}$. If the income of both increases by $100 \%$, the new income of $\mathrm{P}$ is $\$ 200$ and the new income of $\mathrm{R}$ is $\$ 2,000$. The result of this change is that relative inequality remains the same ( $\mathrm{R}$ has still 10 times more income than P), but absolute inequality increases by $\$ 900$ (the gap between the two is now $\$ 1,800$ instead of \$900).
} 
The results of this exercise show that absolute income inequality is a significant determinant of robbery and violent theft rates. In contrast to relative inequality measures, this finding is not affected by the sample size or the consideration of country-specific fixed effects. The main conclusion of our study is therefore twofold: (i) inequality is an important determinant of violent property crime, and (ii) in accordance with economic theory, absolute measures appear to be preferable to relative measures when the impact of inequality on property crime is studied.

The layout of this paper is as follows. Section Two details the theoretical link between absolute inequality and violent property crime. Section Three gives an overview of the research design. Section Four presents and discusses the estimation results. Section Five concludes the paper.

\section{The theoretical link between absolute inequality and violent property crime}

The existing literature identifies various mechanisms through which inequality can foster crime. From a sociological point of view, the most well-known mechanism is social strain theory (Merton, 1938), which in essence argues that criminal behavior is the outcome of dysfunctional social and cultural dynamics that lead to general strain (Agnew, 1985, 1992), institutional anomie (Messner and Rosenfeld, 1997) and relative deprivation (Hagan and Peterson, 1995). To be more precise, according to this literature, inequality (i) contributes to the weakening of social bonds and values ('anomie'), (ii) increases the cultural pressure to be economically successful ('quest for material success'), (iii) lowers the opportunity to achieve economic success in legal ways (imbalance between social goals and the means to achieve them), and (iv) contributes to the subjective feeling of being unjustly disadvantaged in comparison to others ('relative deprivation'). In each of these four scenarios, crime is seen as deviant behavior that serves as outlet for social strain.

The theory of relative deprivation in particular appears to refer to the concept of relative inequality. However, various surveys show that many people compare their status with 
others in absolute, and not relative, terms (Ballano and Ruiz-Castillo, 1993; Harrison and Seidel, 1994; Amiel and Cowell, 1999). Given that some people favor absolute inequality comparisons, while others favor relative inequality comparisons, a priori it is not clear whether the concept of relative or that of absolute inequality is more suited to test the validity of social strain theory.

The analytical framework typically used in economic research is based on Becker's (1968) rational choice model of crime, which leaves aside possible social factors and instead uses a cost-benefit analysis to explain why people commit illegal activities. In Becker's original model, the government chooses the optimal level of law enforcement to prevent criminals from undertaking crimes (i.e., a high probability of being apprehended and of receiving a harsh punishment impedes crime, but simultaneously, it is also costly), while Ehrlich (1973) assumes that under a given level of law enforcement, the individual chooses to engage in illegal activities depending on the potential monetary gains. In other words, Ehrlich's model assumes that rational individuals choose to act in a manner that maximizes their expected net gains.

In essence, Ehrlich's (1973) model is an occupational choice model, in which an individual divides her time between legal $\left(t_{l}\right)$ and illegal $\left(t_{i}\right)$ activities with the aim of maximizing her expected utility. ${ }^{2}$ The income if engaged in legal activities is given by $W_{l}\left(t_{l}\right)$ . When engaging in illegal activities, however, there is a certain probability of being caught and punished $\left(p_{i}\right)$, which implies certain costs $\left(F_{i}\left(t_{i}\right)\right)$ that can reduce the gains of the illegal activity, $W_{i}\left(t_{i}\right)$. The probability of not being caught and punished is $\left(1-p_{i}\right)$. Furthermore, it is assumed that the individual has a stock of net wealth at the beginning of each period $\left(W_{0}\right)$. Finally, to guarantee an interior solution, the model assumes that $W_{i}$ and $W_{l}$ have

\footnotetext{
${ }^{2}$ The complete model presented in Ehrlich (1973) assumes that time is distributed between market (legal and illegal) and non-market activities. To simplify the issue, we assume that the agent does not allocate time to non-market activities. Please note that the conclusion that the crime rate is positively related to absolute inequality is not influenced by this simplification.
} 
diminishing marginal returns (i.e., for every additional unit of time spent, income earned increases to a lesser extent), whereas $F_{i}$ has increasing marginal costs.

Under these considerations, and assuming that time is normalized to one, the total expected income in the case of being caught and punished $\left(X_{a}\right)$ is given by:

$$
X_{a}=W_{0}+W_{i}\left(t_{i}\right)+W_{l}\left(1-t_{i}\right)-F_{i}\left(t_{i}\right),
$$

whereas the expected income when not caught $\left(X_{b}\right)$ is:

$$
X_{b}=W_{0}+W_{i}\left(t_{i}\right)+W_{l}\left(1-t_{i}\right)
$$

Taking $p_{i}$ as exogenous, the individual chooses the values of $t_{i}, t_{l}$ that maximize her expected utility function:

$$
E(U)=p_{i} U\left(X_{a}\right)+\left(1-p_{i}\right) U\left(X_{b}\right)
$$

subject to restrictions (1) and (2).

The first order conditions imply that:

$$
p_{i} U^{\prime}\left(X_{a}\right)\left[w_{i}-w_{l}-f_{i}\right]+\left(1-p_{i}\right) U^{\prime}\left(X_{b}\right)\left[w_{i}-w_{l}\right]=0,
$$

where $w_{i}=\frac{d W_{i}}{d t_{i}} ; w_{l}=\frac{d W_{l}}{d t_{l}} ; f_{i}=\frac{d F_{i}}{d t_{i}}$ and $U^{\prime}(X)=\frac{d U(X)}{d t_{i}}$.

With some algebraic transformations of (4), it follows that:

$$
-\frac{w_{i}-w_{l}}{w_{i}-f_{i}-w_{l}}=\left(\frac{p_{i}}{1-p_{i}}\right) \frac{U^{\prime}\left(X_{a}\right)}{U^{\prime}\left(X_{b}\right)}
$$

The left-hand side of equation (5) shows the slope of the transformation curve of total expected income according to the two possible states of nature (being caught and punished or not). An increase in the time spent engaged in illegal activities raises the income obtained 
from these activities and lowers the income obtained from legal activities, but at the same time, it raises the costs if caught. Hence, when more time is spent in illegal activities, total income increases when not caught, but decreases when caught. ${ }^{3}$ In the optimum, the marginal relation of substitution between the two possible states of nature (right hand side of (5)) should equal the marginal return of both states of nature. That is to say, the individual should not receive additional utility when spending additional time in illegal activities. Considering the diminishing marginal returns and assuming a utility function that is well behaved, the equilibrium position implies that the individual spends time in both activities.

The optimal condition implies that an increase of the left hand side of (5) raises the utility of crime and, as a result, the individual will choose to spend more time in illegal activities. Algebraically, this implies that a necessary condition to increase the time spent in illegal activities is:

$$
w_{i}-w_{l}>p_{i} f_{i}
$$

Expression (6) also implies that "an increase in the marginal or average differential return from illegal activity, $w_{i}-w_{l}$, resulting from an increase in (real) illegitimate payoffs or a decrease in (real) legitimate wages with no change in the other variables entering [equation (5)], can generally be shown to increase the incentive to enter into or allocate more time to illegitimate activity" (Ehrlich, 1973: 530). Accordingly, ceteris paribus, the crime rate "is a positive function of the absolute differential returns from crime" (ibid, 538; italics added). ${ }^{4}$

Unfortunately, information concerning the absolute differential returns of $w_{i}-w_{l}$ is not directly observable. However, an implication of the former analysis is that "the greater the income or wealth of potential victims, the greater will be the expected value of theft. Consequently, income has two conceptual influences on delinquency which operate in

\footnotetext{
${ }^{3}$ Therefore, the transformation curve has a negative slope. The transformation curve is also concave on the grounds that $W_{i}$ and $W_{l}$ have diminishing marginal returns.

${ }^{4}$ (6) also shows that the crime rate is a negative function of being caught and punished. An increase in either $p_{i}$ or $f_{i}$ reduces the incentive to participate in illegal activities (ceteris paribus).
} 
opposite directions" (Fleisher, 1966: 121). It thus follows that from an economic perspective, the most appropriate measures to proxy the net returns from crime are those that conceptualize changes in absolute income differences. ${ }^{5}$

\section{Research design}

The two main data sources of violent property crime used by previous studies are the International Criminal Police Organization (Interpol) and the United Nations Crime Surveys (UNCS). Fanjzylber et al. (2002a, 2002b), for example, use UNCS robbery rates for a sample of 37 countries for the period 1970-1994 (five-year averages), whereas Neumayer (2005) uses Interpol data that allows him to consider robbery and violent theft rates for up to 59 countries for the period 1980-1997 (see Appendix B).

As mentioned in the introduction, when running regressions with a restricted sample of 33 countries that is similar to Fanjzylber et al.'s (2002a, 2002b), Neumayer (2005) finds that inequality is a significant determinant of violent property crime rates (even when adding more control variables than Fanjzylber et al.). However, the significance of inequality vanishes if the sample is broadened to 50-59 countries. Therefore, Neumayer concludes that inequality is not a significant determinant of violent property crime when a representative sample and country-specific fixed effects are used.

Considering the importance of the sample used, that Interpol data on violent property crime is not freely accessible and that the reliability of property crime rates has been

\footnotetext{
${ }^{5}$ Please note that the relation between illegal and legal income would need to be $\left(w_{i} / w_{l}\right)$ for relative measures to be the most appropriate for verifying the influence of inequality on crime. Interestingly, Fanjzylber et al. (2002b) and Neumayer (2005) accept that economic theory refers to absolute income differences, which is evident in the following two quotes: "studies interpreted measures of income inequality as indicators of the distance between the gains from crime and its opportunity costs" (Fanjzylber et al., 2002b, italics added), given that "inequality means a higher concentration of economic wealth in the hands of a few, which implies easier targets for potential criminals and raises the net gains of engaging in violent property crime" (Neumayer, 2005: 101, italics added). Hence, it is puzzling that these studies do not consider absolute inequality measures.
} 
questioned in general $^{6}$, we take advantage of the fact that a replication dataset for Neumayer's (2005) publication is available. ${ }^{7}$ In other words, we use essentially the same data and methodology as Neumayer to ensure that our results are not influenced by the employed research design. The major difference between his and our study, following the theoretical considerations discussed in Section 2, is that instead of relative inequality measures, their absolute counterparts are used as the main variable of interest: our inequality measures are the variance (instead of the Gini Index) and the absolute per capita income difference between the top and bottom quintile of the population (instead of the top-tobottom quintile ratio). ${ }^{8}$

Following Neumayer (2005), we study the impact of income inequality on the three-year averages of the number of robberies and violent thefts per one million inhabitants for the period 1980-1997 with the following model specification:

$$
\ln \left(v c_{i t}\right)=c+X_{i t}^{\prime} \beta+\left(\alpha_{i}+\mu_{i t}\right)
$$

where $i$ represents country, $t$ is time, $\ln (v c)$ is the logged rate of robbery and violent theft, $c$ is a constant, $X^{\prime}$ are the explanatory variables with $\beta$ as the vector of coefficients to be estimated, $\alpha$ represents unobserved individual country effects that are time-invariant, and $\mu$ is the error term.

As mentioned above, our main variables of interest are the variance, which takes into account the entire distribution, and the absolute income difference between the top and bottom quintile (to proxy for the income gap between the poor and the rich). Following

\footnotetext{
${ }^{6}$ Existing crime databases provide very unbalanced data, and it is widely acknowledged that property crime data suffer from methodological changes, different operational definitions between countries, reporting errors, and underreporting (Neapolitan, 1995; Soares, 2004b; Fanjzylber et al., 2002a, 2002b; Neumayer, 2005).

${ }^{7}$ The dataset is available at the website of the Journal of Peace Research (https://www.prio.org/JPR/ Datasets/).

${ }^{8}$ The exact counterpart of the Gini Index is the Absolute Gini Index (AGI); however, we prefer to use the variance on the grounds that the methodology to estimate it also produces the top and bottom income data that we need. The AGI and the variance are highly correlated, and the results presented in Table 3 stay robust when the AGI is used instead of the variance.
} 
Goda and Torres García (2016), we use the Gini coefficients provided by Neumayer (2005) to estimate ventile income shares for each country and year under study (see (9) and (10) in the Appendix for more information). ${ }^{9}$ These income shares are then used to calculate the variance $(V(x))$ :

$$
V(x)=\frac{1}{20} \sum_{p=1}^{20}\left(\left(x_{i p} * G D P_{i}\right)-G D P p c_{i}\right)^{2}
$$

where $x_{i p}$ is the income share of the $p$-th population ventile, $G D P_{p c i}$ is the GDP per capita in purchasing power parity (PPP) of the $i$-th country, and $G D P_{i}$ is the total income of the $i$-th country.

The GPD per capita in PPP as used in this calculation is derived from Neumayer's dataset, while the total income is calculated by multiplying the GDP per capita by the respective population of the country (obtained from World Development Indicators). As shown in (8), we obtain the income of each ventile $\left(x_{i p} * G D P_{i}\right)$ in the process of calculating the variance. These data are used to calculate the absolute difference in the per capita income between the top $20 \%$ and bottom $20 \%$ of the population. Both absolute inequality variables are log-transformed to ease the interpretation of results.

Following Neumayer (2005), the control variables used are the GDP growth rate, unemployment rate, urbanization rate, female labor force participation rate, proportion of males in the age group 15 to 64 , polity measure of democracy, and a measure of human rights violations (Purdue's Political Terror Scales). In addition, Neumayer includes GDP per capita and the square of this variable in his regressions to control for the level of economic development. Given that we use GDP per capita to calculate our measure of absolute inequality (see (8)), we prefer to use the urbanization rate to proxy for the level of development to avoid any potential problems of endogeneity (Neumayer finds that the level

\footnotetext{
${ }^{9}$ Neumayer uses Gini coefficients from the UN-WIDER database (2000), and he adjusts the expenditure Gini coefficients by adding 6.6 Gini points, which is common in the literature to account for the difference between expenditure and income inequality. Ventile income shares allow for relatively exact inequality estimates when income differences within income share groups are not taken into account (see Milanovic, 2012). Each population ventile represents 5\% of the population.
} 
of development has a non-linear effect on violent crime, hence we also include the squared term of the urbanization rate). ${ }^{10}$ The descriptive statistics of all variables considered are reported in Table 1. The corresponding correlation matrix of these variables (Table A1 in the Appendix) indicates that our regressions are not likely to be influenced by multicollinearity.

Table 1: Descriptive statistics of the variables used

\begin{tabular}{lcrrrr}
\hline Variable & Obs & Mean & $\begin{array}{l}\text { Std. } \\
\text { Dev }\end{array}$ & Min & Max \\
\hline $\ln ($ Violent Crime Rate) & 206 & 5.58 & 1.45 & 0.21 & 7.91 \\
$\ln ($ Variance) & 206 & 17.21 & 1.84 & 12.37 & 20.50 \\
$\ln ($ Top20-Bottom20) & 206 & 9.55 & 0.93 & 7.16 & 11.13 \\
\%Urban & 206 & 63.94 & 21.20 & 11.20 & 100.00 \\
Economic Growth & 206 & 0.97 & 4.90 & -17.81 & 14.49 \\
Unemployment Rate & 183 & 7.57 & 4.36 & 0.73 & 21.20 \\
Femle Labor Force Part. & 206 & 37.05 & 9.97 & 7.47 & 55.63 \\
\%Male 15-64 & 206 & 0.32 & 0.03 & 0.23 & 0.36 \\
Democracy & 206 & 15.91 & 5.98 & 0.00 & 20.00 \\
Human Rights Violation & 206 & 1.86 & 1.02 & 1.00 & 4.83 \\
\hline
\end{tabular}

Finally, it is important to mention that Neumayer uses fixed effects, random-effects and dynamic systems generalized method of moments (GMM) estimator regressions for his analysis. We abstain from reporting results obtained with dynamic GMM estimators, on the grounds that due to the need to use lagged values to instrument the dependent variable, the sample size becomes very small ( $<120$ observations), which is likely to lead to a substantial loss of efficiency (Wooldridge, 2002). This issue might explain why all explanatory variables in Neumayer's (2005) paper either change their sign or their significance when dynamic system GMM estimators are used instead of the fixed-effects models. This is likely to be the reason why Neumayer concentrates his analysis on the results obtained with fixedeffects models.

\footnotetext{
${ }^{10} \mathrm{~A}$ broad consensus exists in the literature that economic development inevitably entails an increase in the urbanization rate (Todaro and Smith, 2012, Ch. 7). The correlation between the urbanization rate and GDP per capita in 1997 PPP is positive and above $80 \%$.
} 
A potential problem with the presented regressions could be endogeneity. However, it is not clear a priori if higher crime rates affect inequality because the amount of crime might not be sufficiently large to influence the general inequality structure. More importantly, as outlined in Section Two, theory expects crime to have a negative effect on inequality (i.e., more crime is expected to decrease inequality). Considering that the presented inequality coefficients have a positive sign and are statistically significant, it appears that endogeneity is either not present or that the inequality-reducing effect of crime is lower than the positive effect of inequality on violent crime. The latter case would influence the presented inequality coefficient values; however, given that our main interest is the sign and statistical significance, we conclude that potential endogeneity problems do not influence our main finding that absolute inequality fosters violent crime.

\section{The impact of absolute income inequality on violent property crime}

Table 2 presents the estimation results using the variance as the absolute inequality measure. Model (i) is a fixed-effects regression in which the sample size is reduced to 33 countries with the aim of considering only those countries that are included in Fanjzylber et al. (2002b). In agreement with the Gini Index that is used by Fanjzylber et al. and Neumayer (2005), the variance has a positive sign and is statistically significant. The positive and significant effect of the variance stays robust when more control variables are added, as shown in Model (ii). This finding is also in line with the relative inequality results presented by Fanjzylber et al. and Neumayer.

According to Model (ii), on average, a $1 \%$ increase in the variance leads to a $0.47 \%$ increase in the robbery and violent theft rate. Other important variables to explain violent property crime are the unemployment rate, the female labor force participation rate, the level of democracy, and the degree of human rights violation in the country. All of these control variables have the expected positive sign. Given that these results are similar to Neumayer's (2005) results, it can be concluded that with a reduced sample size, the overall results 
obtained are consistent irrespective of whether the variance or the Gini Index is the inequality measure.

Table 2: The effect of income variance on violent property crime

\begin{tabular}{|c|c|c|c|c|c|c|}
\hline & $\begin{array}{l}\text { (i) } \\
\text { FE }\end{array}$ & $\begin{array}{l}\text { (ii) } \\
\text { FE }\end{array}$ & $\begin{array}{l}\text { (iii) } \\
\text { FE }\end{array}$ & $\begin{array}{l}\text { (iv) } \\
\text { FE }\end{array}$ & $\begin{array}{l}\text { (v) } \\
\text { FE }\end{array}$ & $\begin{array}{l}\text { (vi) } \\
\text { RE }\end{array}$ \\
\hline $\ln ($ Variance $)$ & $\begin{array}{c}0.544 \\
(3.95)^{* * *}\end{array}$ & $\begin{array}{c}0.474 \\
(3.27) * * *\end{array}$ & $\begin{array}{c}0.331 \\
(3.48) * * * *\end{array}$ & $\begin{array}{l}0.226 \\
(2.02) * *\end{array}$ & $\begin{array}{l}0.202 \\
(1.90) *\end{array}$ & $\begin{array}{c}0.305 \\
(3.59) * * * *\end{array}$ \\
\hline$\%$ Urban & $\begin{array}{l}0.008 \\
(0.33)\end{array}$ & $\begin{array}{l}-0.075 \\
(-1.27)\end{array}$ & $\begin{array}{c}0.038 \\
(2.62)^{* *}\end{array}$ & $\begin{array}{l}0.033 \\
(0.77)\end{array}$ & & $\begin{array}{c}0.062 \\
(2.29)^{* *}\end{array}$ \\
\hline \%Urban squared & & $\begin{array}{l}-.000 \\
(-0.29)\end{array}$ & & $\begin{array}{l}-.001 \\
(-1.21)\end{array}$ & & $\begin{array}{c}-.000 \\
(-1.75)^{*}\end{array}$ \\
\hline Economic growth & $\begin{array}{l}-0.014 \\
(-1.16)\end{array}$ & $\begin{array}{l}-0.016 \\
(-1.47)\end{array}$ & $\begin{array}{l}-0.005 \\
(-0.59)\end{array}$ & $\begin{array}{l}-0.008 \\
(-0.93)\end{array}$ & & $\begin{array}{l}-0.011 \\
(-1.26)\end{array}$ \\
\hline Unemployment rate & & $\begin{array}{c}0.059 \\
(2.99)^{* * *}\end{array}$ & & $\begin{array}{c}0.033 \\
(1.98)^{* *}\end{array}$ & $\begin{array}{c}0.026 \\
(1.67)^{*}\end{array}$ & $\begin{array}{c}0.060 \\
(4.05)^{* * *}\end{array}$ \\
\hline Female labor force part. & & $\begin{array}{c}0.045 \\
(1.89)^{*}\end{array}$ & & $\begin{array}{c}0.069 \\
(3.17)^{* * *}\end{array}$ & $\begin{array}{c}0.066 \\
(3.50)^{* * *}\end{array}$ & $\begin{array}{c}0.032 \\
(2.62)^{* * *}\end{array}$ \\
\hline$\%$ Male 15-64 & & $\begin{array}{l}13.206 \\
(1.42)\end{array}$ & & $\begin{array}{l}3.607 \\
(0.48)\end{array}$ & & $\begin{array}{l}-5.743 \\
(-1.02)\end{array}$ \\
\hline Democracy & & $\begin{array}{c}0.077 \\
(4.34)^{* * *}\end{array}$ & & $\begin{array}{c}0.054 \\
(3.33)^{* * *}\end{array}$ & $\begin{array}{c}0.049 \\
(3.34)^{* * *}\end{array}$ & $\begin{array}{c}0.039 \\
(2.64)^{* * *}\end{array}$ \\
\hline Human rights violations & & $\begin{array}{c}0.520 \\
(3.54)^{* * *} \\
\end{array}$ & & $\begin{array}{c}0.308 \\
(2.59)^{* *} \\
\end{array}$ & $\begin{array}{c}0.345 \\
(3.04)^{* * *} \\
\end{array}$ & $\begin{array}{c}0.227 \\
(2.47)^{* *} \\
\end{array}$ \\
\hline Observations & 134 & 134 & 203 & 182 & 182 & 182 \\
\hline Number of countries & 33 & 33 & 58 & 50 & 50 & 50 \\
\hline R-squared & 0.21 & 0.48 & 0.19 & 0.40 & 0.39 & 0.35 \\
\hline $\begin{array}{l}\text { Hausman test chi-squared } \\
\text { (p-value) }\end{array}$ & & & & & & $\begin{array}{l}59.72 \\
(0.00) \\
\end{array}$ \\
\hline
\end{tabular}

Notes: This table summarizes the results of our panel data models for the logarithm of robbery and violent theft rates (three-year averages for the period 1980-1997). FE stands for fixed effects and RE for random effects. The values in parenthesis are t-statistics. All models include a constant that is not reported in the table. The significance of a coefficient or test statistic at the 1\%, 5\% and $10 \%$ level of significance is indicated by ***,** and *, respectively,

When the artificial sample size restriction of Models (i) and (ii) is lifted and the entire sample is considered, the effect of the variance on violent property crime reduces along with the explanatory power of the model (Model (iii)). Nevertheless, the effect of absolute income inequality on violent property crime stays positive and significant at the $1 \%$ level. Model (iv) and Model (v) show that the effect of absolute inequality remains positive and 
significant, at least at the $10 \%$ level, when either all control variables are considered or only those that are statistically significant.

In our parsimonious fixed-effects Model (v), a $1 \%$ increase in the variance leads to a $0.2 \%$ increase in the violent property crime rate. According to this model, higher unemployment and female labor force participation rates, as well as a higher degree of democracy and human rights violations, also foster violent property crime (please note that these results are in accordance with the reduced sample size Model (ii)). Finally, it is important to note that the R-squared value of 0.39 suggests that the variation in violent property crime rates is explained reasonably well by this model.

Our key finding is that income inequality is a statistically significant determinant of violent property crime when unobserved country specific effects are considered and the sample is representative; this result is in sharp contrast with the results presented by Neumayer (2005). As discussed above, Neumayer finds that income inequality (when measured by the Gini coefficient) is no longer statistically significant when the sample is increased to 59 countries and fixed-effects models are used. The strong discrepancy between our and Neumayer's results has important implications. First, our results support economic theory that states that absolute differential returns between legal and illegal activities are an important determinant of crime. Second, the presented results reaffirm the widely made claim that inequality is a major cause of violent property crime. Third, the omission of absolute inequality measures in empirical studies on the correlates of crime appears to be a major shortcoming that can lead to incorrect conclusions about the impact of inequality on crime.

Finally, Model (vi) replicates Model (iv) but uses random-effects instead of fixed effects. The results show that the main results are not influenced by this change in the estimation method. The only important difference is that in the random-effects model, the variables urban and urban squared become significant with the expected signs (i.e., economic development leads to an increase in violent property crime, but at a slightly decreasing rate). 
However, the last row of Table 3 shows that the Hausman test suggests that the results of the fixed-effects Model (iv) are preferable over those of the random-effects Model (vi).

Following Neumayer (2005), we repeat the analysis of Table 2 using an alternative inequality measure that considers the income differences between the poor and the rich. In our case, this alternative measure is the logarithm of the absolute per capita income difference between the top and bottom quintile. Table 3 shows that the obtained results are very similar when using this alternative absolute measure. Especially noteworthy is that the absolute inequality measure is statistically significant and positive in all specifications. In our parsimonious Model (v), a 1\% increase in the absolute income difference between the top and the bottom leads to a $0.43 \%$ increase in the violent property crime rate. This result suggests that increases in absolute inequality between the top and the bottom have stronger effects on violent property crime than absolute inequality increases between other parts of the distribution.

The results are also robust in the sense that the values and significance of the control variables reported in Table 3 are very similar to those reported in Table 2 and that the Hausman test shows that the fixed-effects Model (iv) is preferable to the random-effects Model (vi). This similarity in the results is not surprising given the very high correlation between the two inequality measures (see Table 2). In conclusion, the results of Table 3 support our key finding that absolute inequality is an important determinant of violent property crime irrespective of the sample size and the consideration of unobserved country specific effects. 
Table 3: The effect of top-bottom income differences on violent property crime

\begin{tabular}{|c|c|c|c|c|c|c|}
\hline & $\begin{array}{l}\text { (i) } \\
\text { FE }\end{array}$ & $\begin{array}{l}\text { (ii) } \\
\text { FE }\end{array}$ & (iii) & $\begin{array}{l}\text { (iv) } \\
\text { FE }\end{array}$ & $\begin{array}{l}\text { (v) } \\
\text { FE }\end{array}$ & $\begin{array}{l}\text { (vi) } \\
\text { RE }\end{array}$ \\
\hline $\ln ($ top-bottom) & $\begin{array}{c}1.178 \\
(4.00) * * *\end{array}$ & $\begin{array}{c}1.054 \\
(3.36)^{* * * *}\end{array}$ & $\begin{array}{c}0.699 \\
(3.46) * * *\end{array}$ & $\begin{array}{c}0.492 \\
(2.05) * *\end{array}$ & $\begin{array}{c}0.433 \\
(1.92)^{*}\end{array}$ & $\begin{array}{c}0.637 \\
(3.53) * * *\end{array}$ \\
\hline$\%$ Urban & $\begin{array}{l}0.003 \\
(0.12)\end{array}$ & $\begin{array}{l}-0.082 \\
(-1.39)\end{array}$ & $\begin{array}{c}0.037 \\
(2.50)^{* *}\end{array}$ & $\begin{array}{l}0.032 \\
(0.74)\end{array}$ & & $\begin{array}{c}0.061 \\
(2.25)^{* *}\end{array}$ \\
\hline$\%$ Urban squared & & $\begin{array}{c}-.000 \\
(-0.22)\end{array}$ & & $\begin{array}{c}-.000 \\
(-1.20)\end{array}$ & & $\begin{array}{c}-.000 \\
(-1.73)^{*}\end{array}$ \\
\hline Economic growth & $\begin{array}{l}-0.014 \\
(-1.18)\end{array}$ & $\begin{array}{l}-0.016 \\
(-1.49)\end{array}$ & $\begin{array}{l}-0.005 \\
(-0.64)\end{array}$ & $\begin{array}{l}-0.008 \\
(-0.94)\end{array}$ & & $\begin{array}{l}-0.010 \\
(-1.23)\end{array}$ \\
\hline Unemployment rate & & $\begin{array}{c}0.060 \\
(3.05)^{* * *}\end{array}$ & & $\begin{array}{c}0.033 \\
(2.99)^{* *}\end{array}$ & $\begin{array}{c}0.026 \\
(1.69)^{*}\end{array}$ & $\begin{array}{c}0.060 \\
(4.01)^{* * * *}\end{array}$ \\
\hline Female labor force part. & & $\begin{array}{c}0.043 \\
(1.80)^{*}\end{array}$ & & $\begin{array}{c}0.068 \\
(3.14)^{* * * *}\end{array}$ & $\begin{array}{c}0.065 \\
(3.40)^{* * * *}\end{array}$ & $\begin{array}{c}0.032 \\
(2.63)^{* * * *}\end{array}$ \\
\hline$\%$ Male $15-64$ & & $\begin{array}{l}12.535 \\
(1.35)\end{array}$ & & $\begin{array}{l}3.183 \\
(0.42)\end{array}$ & & $\begin{array}{l}-6.346 \\
(-1.12)\end{array}$ \\
\hline Democracy & & $\begin{array}{c}0.078 \\
(4.39)^{* * *}\end{array}$ & & $\begin{array}{c}0.054 \\
(3.34)^{* * * *}\end{array}$ & $\begin{array}{c}0.049 \\
(3.32)^{* * * *}\end{array}$ & $\begin{array}{c}0.039 \\
(2.66)^{* * * *}\end{array}$ \\
\hline Human rights violations & & $\begin{array}{c}0.526 \\
(3.58)^{* * *}\end{array}$ & & $\begin{array}{c}0.310 \\
(2.61)^{* *}\end{array}$ & $\begin{array}{c}0.346 \\
(3.05)^{* * *}\end{array}$ & $\begin{array}{c}0.236 \\
(2.55)^{* *}\end{array}$ \\
\hline Observations & 134 & 134 & 203 & 182 & 182 & 182 \\
\hline Number of countries & 33 & 33 & 58 & 50 & 50 & 50 \\
\hline $\begin{array}{l}\text { R-squared } \\
\text { Hausman test chi-squared } \\
\text { (p-value) }\end{array}$ & 0.22 & 0.48 & 0.19 & 0.40 & 0.39 & $\begin{array}{l}0.35 \\
53.41 \\
(0.00)\end{array}$ \\
\hline
\end{tabular}

Notes: Please see the notes for Table 2.

\section{Conclusions}

The presented results suggest that absolute inequality is a statistically significant determinant of robbery and violent theft rates, irrespective of whether measured by the variance or by the absolute per capita income difference between the top and bottom quintiles. This finding supports economic rational choice models that state that absolute differential returns between legal and illegal activity are an important determinant of crime.

Contrary to Neumayer's (2005) findings, our results are robust when the sample is as representative as possible and unobserved country specific effects are considered. The 
presented results not only reaffirm Fanjzylber et al.'s (2002a, 2002b) claim that inequality is a major cause of violent property crime but also suggest that the omission of absolute inequality is a major weakness in the existing studies on the correlates of crime. Thus, future

crime research should consider relative as well as absolute inequality measures to verify whether absolute measures are also more robust than inequality indicators in other settings (e.g., when non-violent property crimes are considered or in single-country studies).

Important policy implication of our analysis are that robbery and violent theft rates could be lowered by reducing absolute income differences and that economic growth does not lower violent property crime rates (not only because this variable is not statistically significant but also on the grounds that economic growth without redistribution automatically results in increasing absolute income differences). Other important determinants of crime that governments should take into consideration when aiming to reduce violent property crime rates are the unemployment rate, the level of democracy, and the degree of human rights violations.

\section{References}

Agnew, Robert (1985) A revised strain theory of delinquency. Social Forces 64(1): 151-167.

Agnew, Robert (1992) Foundation for a general strain theory of crime and delinquency. Criminology 30(1): 47-87.

Amiel, Yoram, \& Frank Cowell (1999) Thinking about Inequality: Personal Judgment and Income Distributions. Cambridge: Cambridge University Press.

Atkinson, Anthony \& Andrea Brandolini (2010) On analyzing the world distribution of income. World Bank Economic Review 24(1): 1-37.

Ballano, Carlos \& Javier Ruiz-Castillo (1993) Searching by questionnaire for the meaning of income inequality. Revista Español de Economía 10(2): 233-259.

Becker, Gary S (1968) Crime and punishment: An economic approach. Journal of Political Economy 76(2): 169-217.

Bennett, Richard R (1991). Development and Crime: A cross-national, time-series analysis of competing models. Sociological Quarterly 32(3): 343-363. 
Bosmans, Kristof; Koen Decancq \& André Decoster (2014) The relativity of decreasing inequality between countries. Economica 81(322): 276-292.

Chakravarty, Satya R (2001) The variance as a subgroup decomposable measure of inequality. Social Indicators Research 53(1): 79-95.

Chiu, Henry \& Paul Madden (1998) Burglary and income inequality. Journal of Public Economics 69(1): 123-141.

Ehrlich, Isaac (1973) Participation in illegitimate activities: A theoretical and empirical investigation. Journal of Political Economy 81(3): 521-565.

Fajnzylber, Pablo; Daniel Lederman \& Norman Loayza (2002a) What causes violent crime? European Economic Review 46(7): 1323-1356.

Fajnzylber, Pablo; Daniel Lederman \& Norman Loayza (2002b) Inequality and violent property crime. Journal of Law and Economics 45(1): 1-40.

Fleisher, Belton M (1966) The effect of income on delinquency. American Economic Review 56(1/2): 118-137.

Goda, Thomas (2016) Global trends in relative and absolute income inequality. Ecos de Economía 20(42): 46-69.

Goda, Thomas \& Alejandro Torres García (2016) The rising tide of absolute global income inequality during 1850-2010: Is it driven by inequality within or between countries? Social Indicators Research, 1-22. doi:10.1007/s11205-015-1222-0.

Hagan, John \& Ruth D Peterson (1995) Criminal inequality in America: Patterns and consequences. In: John Hagan \& Ruth D Peterson (eds) Crime and Inequality. Stanford: Stanford University Press, 14-36.

Harrison, Elizabeth \& Christian Seidl (1994) Perceptional inequality and preferential judgements: An empirical examination of distributional axioms. Public Choice 79(1-2): 61-81.

Merton, Robert K (1938) Social structure and anomie. American Sociological Review 3(5): 672-682.

Messner, Steven F \& Richard Rosenfeld (1997) Political restraint of the market and levels of criminal homicide: A cross-national application of institutional-anomie theory. Social Forces 75(4): 1393-1416.

Milanovic, Branko (2012) Global inequality recalculated and updated: the effect of new PPP estimates on global inequality and 2005 estimates. Journal of Economic Inequality 10(1): $1-18$.

Neapolitan, Jerry (1995) Differing theoretical perspectives and cross-national variation in thefts in less developed nations. International Criminal Justice Review 5(1): 17-31. 
Neumayer, Eric (2005) Inequality and violent crime: Evidence from data on robbery and violent theft. Journal of Peace Research 42(1): 101-112.

Nivette, Amy E (2011) Cross-national predictors of crime: A meta-analysis. Homicide Studies 15(2): 103-131.

Ravallion, Martin (2004) Competing concepts of inequality in the globalization debate. In: Susan Collins \& Carol Graham, (eds) Brookings Trade Forum 2004. Globalization, Poverty, and Inequality. Washington, DC: Brookings Institution Press, 1-38.

Soares, Rodrigo (2004a) Crime reporting as a measure of institutional development. Economic Development and Cultural Change 52(4): 851-871.

Soares, Rodrigo (2004b) Development, crime and punishment: Accounting for the international differences in crime rates. Journal of Development Economics 73(1): 155184.

Stack, Steven (1984) Income Inequality and Property Crime: A cross-national analysis of relative depreviation theory. Criminology 22(2): 229-257.

Sun, Ivan; Doris C Chu \& Hung-En Sung (2011) A cross-national analysis of the mediating effect of economic deprivation on crime. Asian Journal of Criminology 6(1): 15-32.

Todaro, Michael P \& Stephen C Smith (2012) Economic Development. Boston, MA: Addison-Wesley.

van Zanden, Jan L, Joerg Baten, Peter Foldvari \& Bas van Leeuwen (2014) The Changing Shape of Global Inequality 1820-2000: Exploring a new dataset. Review of Income and Wealth 60(2): 279-97.

Wooldridge, Jeffrey M (2002) Analysis of Cross-Sectional and Panel Data. Cambridge: MIT Press. 


\section{APPENDIX}

\section{A. Calculation of ventile income shares}

The variance income shares for each country and year under study are required (see (8). Following Goda \& Torres García (2016) and van Zanden et al. (2014), we suppose a lognormal distribution. Under this assumption, the relationship between the Gini coefficient and the Lorenz curve can be expressed as follows:

$$
L(p)=\Phi\left(\Phi^{-1}(p)-\sigma_{i}\right)
$$

where $\Phi$ is the lognormal cumulative distribution function of income, $p$ is the percentile of the distribution, and $\sigma_{i}$ is the standard deviation, which is associated with the Gini coefficient of each country and year under study as shown by the following expression:

$$
\sigma_{i}=\sqrt{2} \Phi^{-1}\left(\frac{1+G_{i}}{2}\right)
$$

where $G_{i}$ is the Gini coefficient of the $i$-th country.

\section{B. Sample Countries}

Neumayer (2005) only considers those countries that have more than one observation:

Armenia, Australia, Austria, Bangladesh, Belgium, Bulgaria, Canada, Chile, China, Colombia, Costa Rica, Côte d'Ivoire, Denmark, Ecuador, Estonia, Finland, France, Georgia, Germany, Ghana, Greece, Guinea, Honduras, Hungary, India, Indonesia, Ireland, Israel, Italy, Jamaica, Japan, Jordan, Latvia, Luxembourg, Malaysia, the Netherlands, New Zealand, Norway, Pakistan, Philippines, Poland, Portugal, Romania, Russian Federation, Senegal,

Singapore, Slovak Republic, South Korea, Spain, Sri Lanka, Sweden, Switzerland, Thailand, Uganda, Ukraine, United Kingdom, USA, Venezuela, and Zambia. 


\section{Correlation Matrix}

Table A1: Correlation Matrix of Variables after Fixed-Effects Transformation

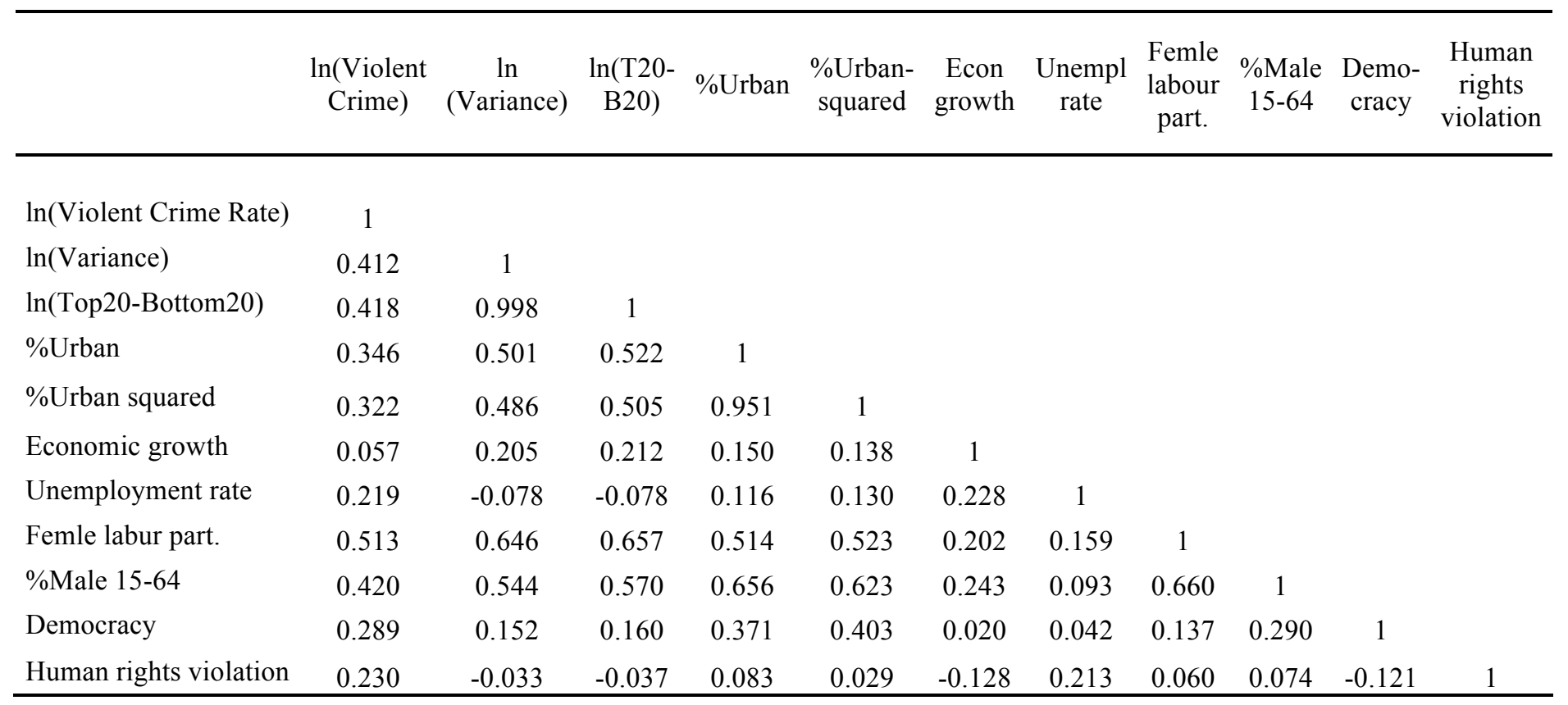

